\title{
BUILDING CAPACITY IN INJURY RESEARCH TRANSFER
}

\section{Roslyn Poulos and Anthony Zwi}

School of Public Health and Community Medicine

The University of New South Wales

This paper was written on behalf of the Injury, Trauma, Rehabilitation Partnership (see Box 1)

\section{BACKGROUND}

Injury is a leading cause of mortality, morbidity and disability in Australia. In recognition of the national burden of injury, the area of injury prevention and control was endorsed as a national health priority in 1986. Despite this, however, there has been a substantial mismatch between the identification of injury as a problem and the level of funding available for injury research. ${ }^{1}$ Late in 2004, a NSW consortium of academic institutions (Box 1) was awarded a five-year National Health and Medical Research Council Capacity Building Grant in Population Health Research to build capacity in population approaches to injury prevention and control. Four injury domains were identified for ongoing research (road safety, falls, sports and work-related injuries) across a number of thematic areas, one of which includes the translation of injury research into policy and practice.

Enhancing the interface between research on the one hand, and policy and practice on the other, is crucial to ensuring the widespread adoption of effective interventions and strategies. The literature abounds with theories on how to improve 'linkage and exchange', yet empirical research remains limited. This paper builds upon the concept of a Translation Task Group, which was suggested by one of the authors (Zwi) as a component of the Capacity Building Grant. The concept has developed its own momentum and is a structure through which to broker productive relationships between researchers, policy makers, practitioners and other stakeholders. This paper reports some of the early outcomes of Translation Task Group activity to address injury.

\section{THE ROLE OF TRANSLATION TASK GROUPS}

As part of the Capacity Building Grant, we have developed with our consortium researchers two Translation Task Groups, one focusing on road safety and the other on falls. Currently, both groups comprise internationally recognised researchers and a number of early career researchers. Initial meetings have been held to identify the role of such groups and to determine appropriate membership. These meetings also recognised the need to form, in the near future, a further Translation Task Group with a focus on Indigenous safety. This group will traverse the injury domains and address specific issues of relevance to the Indigenous community with respect to the development and implementation of injury prevention and safety policies.

For the purpose of the project we have defined a Translation Task Group as 'a group that is able to enhance linkage and exchange between researchers, policy makers and other stakeholders, and to foster the development of policy- sensitive researchers and evidence-sensitive policy makers with the aim of improving the development of policy appropriate research and improving the dissemination and uptake of research into policy and practice'. It is intended that membership be broadened to a wider range of stakeholders including ${ }^{3}$ :

- government representatives who have the potential to facilitate the presentation of research evidence at policy making forums

- practitioners who can apply new knowledge to practice

- social marketers and health journalists, who have the potential to stimulate wider interest

- representatives from relevant community groups, who may assist and enable the dissemination of information to the public.

All of these groups will have a role in influencing the research agenda.

Although only in their very early stages, the Translation Task Groups are already proving beneficial. First, they provide the opportunity for researchers in common theme areas, but from different institutions, to come together and reflect on their respective and combined experiences. This has led to the identification of a number of common difficulties in facilitating the transition of research into policy and practice, which can later be addressed. For example, among the road safety researchers there was an appreciation that research evidence was only one influence among many political priorities. The perception of scientific naiveté of policy makers, the turnover of ministerial advisory staff and the lack of scientific consensus in the field were among the significant barriers identified. Researchers in falls prevention with a focus on falls in older people identified some significant successes with clear evidence-informed policy already in place. ${ }^{4}$

In terms of enhancing the research-policy interface, both Translation Task Groups identified personal contact with policy makers as the most critical factor in getting evidence into policy and practice. Two-way communication aids both the dissemination of emerging research and the setting of the research agenda. ${ }^{5}$ Translation Task Groups were recognised as a forum through which this communication could be enhanced.

Second, the groups have identified areas in which researchers require development of their skills. Both groups recognised the need to influence and interact with the policy process rather than assume that the evidence would speak for itself. ${ }^{6,7}$ Researchers felt limited in their ability to advocate for policy change, not only because this takes time, but also because they felt they lacked the skills necessary to be effective policy advocates. Similarly, an improved understanding of the policy making process was sought. It has been recognised that policy making is a 'messy and convoluted process' ${ }^{6}$ which is an enigma to 
many outside government bureaucracy and that 'researchers need to acquire a more sophisticated understanding of the policy process'. ${ }^{3}$ An active program of skill development in this area is planned in the next six months and will be assessed in terms of its effectiveness in enhancing linkage and exchange. It will be important, within this agenda, to improve understanding of the policy-related roles of a wide range of actors operating within the policy environment, as policy makers are themselves not a homogeneous group.

Finally, the initial meetings have generated a new research agenda describing the process of translation. The road safety group has formulated a methodology for a qualitative study to examine the experiences of established researchers in order to document the barriers to, and facilitators of, research uptake and dissemination in the area of road safety. It is planned that this research will inform the ongoing role of the group and aid in the determination of its membership. The falls group has identified a successful Health Research Partnership Grant as a model for how policy makers, researchers, practitioners, government and private enterprise can work effectively together to set research agendas and disseminate evidence. Research to document this apparently successful process is planned.

\section{EVALUATION}

Indicators of the contribution of Translation Task Groups will need to include measures of process, impact and outcome. While these are yet to be defined, initial suggestions have included measures such as the number of groups established with consideration of the range and breadth of stakeholders and the regularity of meetings; the creation of educational activities designed to meet the needs of members (for example, policy training for researchers, or research training for policy makers); actions around policy and practice arising directly from the groups (for example, new dissemination strategies for emerging research, ministerial briefings, media activities); new research partnerships between stakeholders; and scientific presentations and peer-reviewed papers on our research at the translation interface.

Outcome measures, however, will prove the most challenging to evaluate. While some research may be directly incorporated into policy, this is rare and most research is likely to act through a much slower and indirect route $^{8}$, and may entail a process of adoption, adaptation and action. ${ }^{9}$ However, in such cases, attributing policy change to a particular research intervention or output will be difficult.

In addition to the specific research agenda arising from individual Translation Task Groups, we are studying the formation and function of the groups as part of an action research agenda that combines our desire to both change practice and enhance knowledge. Consequently, group members will be actively involved throughout the process of the study, so that their discussions and reflections on the process informs subsequent stages of both the research and the implementation of the groups. We hypothesise that a Translation Task Group will be an effective instrument through which to promote policy-sensitive research and effect knowledge transfer. Adaptations on the concept may also be applicable to other research areas. Our findings should provide empirical data on which to develop strategies to maximize the contribution of Australian injury research to policy and practice.

\section{ACKNOWLEDGEMENT}

Roslyn Poulos was supported in carrying out this work by a National Health and Medical Research Council Population Health Capacity Building Grant in Injury Prevention, Trauma and Rehabilitation.

\section{BOX 1}

\section{MEMBERSHIP OF THE INJURY, TRAUMA, REHABILITATION PARTNERSHIP}

Injury, Trauma, Rehabilitation is a collaborative program auspiced by the NSW Injury Risk Management Research Centre, the University of New South Wales; the George Institute for International Health, the University of Sydney; the Prince of Wales Medical Research Institute, the University of New South Wales; the School of Public Health and Community Medicine, the University of New South Wales; and the Rehabilitation Studies Unit, the University of Sydney.

\section{REFERENCES}

1. National Health and Medical Research Council. Paradigm shift. Injury: from problem to solution. New research directions. Canberra: NHMRC, 1999.

2. Lomas J. Using 'linkage and exchange' to move research into policy at a Canadian Foundation. Health Aff, 2000. 19(3): 236-40.

3. Black N. Evidence based policy: proceed with care. $B M J$ 2001; 323: 275-8.

4. NSW Department of Health. Management policy to reduce fall injury among older people. Sydney, NSW Department of Health, 2003.

5. Innvaer S, Vist G, Trommald M, Oxman A. Health policy makers' perceptions of their use of evidence: a systematic review. J Health Serv Res Policy 2002. 7(4): 239-44.

6. Sommer A. How public health policy is created: scientific process and political reality. Am J Epidemiol 2001. 154(12, Suppl): S4-S6.

7. Lavis JN, Robertson D, Woodside JM, McLeod CM, Abelson J. How can research organizations more effectively transfer research knowledge to decision makers. The Milbank Quarterly 2003. 81(2): 221-48.

8. Weiss $\mathrm{CH}$. The many meanings of research utilization. Public Adm Rev 1979. Sept/Oct: 426-31.

9. Bowen S, Zwi AB. Pathways to 'evidence-informed' policy and practice: A framework for action. PLoS Med 2005; 2(7), e166. Available at: http://medicine.plosjournals.org/ archive/1549-1676/2/7/pdf/10.1371_journal.pmed.0020166L.pdf. Accessed 10 March 2006. 图 